\title{
The Giver: A Case Study of the Impact of Remote Music Collaboration Software on Music Production Process
}

\author{
Martin K. Koszolko \\ Melbourne Polytechnic \\ MartinKoszolko@melbournepolytechnic.edu.au
}

\begin{abstract}
The development of Web 2.0 combined with the emergence of innovative software platforms has helped remote music collaboration undergo a phase of significant growth in the last five years. My practice-led research responds to the question of how working with remote music collaboration software (RMCS) impacts on the production process. The discussion and the sound recording accompanied by this paper concern one example of my collaborative practice using Ohm Studio software. I created a popular music piece titled "The Giver" with creative contributors located on three continents. My analysis shows that RMCS offers music producers innovative ways to network and develop a project with the input of globally crowdsourced participants. The resulting sound recording exemplifies an RMCS-based process that led to changes in production workflow, facilitated learning, generated new creative relationships, and, ultimately, helped to achieve the desired musical outcomes.
\end{abstract}

KEYWORDS: collaboration, RMCS, Ohm Studio, music production

The compositions that are part of this study can be found here:

Stage One:

http://www.iaspmjournal.net/index.php/IASPM_Journal/article/downloadSuppFile/822/242

Stage Two:

http://www.iaspmjournal.net/index.php/IASPM Journal/article/downloadSuppFile/822/259

Stage Three:

http://www.iaspmjournal.net/index.php/IASPM_Journal/article/downloadSuppFile/822/260

IASPM@Journal vol.7 no.2 (2017)

Journal of the International Association for the Study of Popular Music

ISSN 2079-3871 I DOI 10.5429/2079-3871(2017)v7i2.6en I www.iaspmjournal.net 


\section{Context, aims, and methodology}

Contemporary remote music collaboration software (RMCS) offers producers social networking and music production tools that allow for cloud-based creation of musical pieces with the input of globally crowdsourced participants. My practiceled research responds to the question of how working with RMCS impacts on the production process. This paper is situated in the scholarly field of the art of record production (see, for example, Frith and Zagorski-Thomas 2012; Burgess 2013) and the primary research method used in my work is practitioner-based enquiry. As highlighted by McIntyre, this methodology "encompasses a self-reflective examination of the practitioner's own activity through a process of participation in that activity" (2006). The outputs of this project align with Smith and Dean's view that "creative work in itself is a form of research and generates detectable research outputs" (2009: 5).

There is a body of academic work on early, networked music collaboration (Barbosa 2003; Duckworth 2005; Hugill 2005), as well as developments in the area of synchronous networked music performances (Alexandraki and Valsamakis 2009; Whalley and Fields 2012; Whalley 2016). RMCS-based music production, while utilizing networked musical environments, is primarily concerned with the music recording and production process. While synchronous collaboration is frequent, asynchronous work is often performed as well. RMCS provides spaces where social networking tools can be utilized to crowdsource musical input (Koszolko 2015) and represents a development in what Théberge described as the network studio (2004). My research on RMCS discusses recent developments of collaborative technologies which afford new ways of networking, communicating, and creating musical content in the confines of globally dispersed recording studios.

The piece discussed here and titled "The Giver" was created with the use of Ohm Studio. It was part of a larger research project investigating a broader range of RMCS tools and production strategies. Ohm Studio is a standalone digital audio workstation (DAW), which facilitates synchronous and asynchronous work and includes a range of music production features typical of professional DAWs. Communication is facilitated in multiple ways: In addition to private messaging and synchronous public and private chat rooms, users have the ability to communicate with other project members asynchronously via the built-in system of "sticky notes" 1 .

In order to measure the impact of RMCS on collaborative music production practices, I have examined such factors as the technical feasibility of RMCS, opportunities and challenges of the various communication methods, and effectiveness of available approaches to facilitate user engagement in crowdsourced projects. Furthermore, I analysed the musical output of my creative practice, which constitutes the practical component of my research. However, due to limited space, the discussion below highlights only selected aspects of my analysis.

The presented audio recording was initiated during one of the regular collaborative events facilitating music production between members of the Ohm Studio community of musicians. These events function as a catalyst to bring users of various levels of experience together. I engaged in a collaborative project with the aim of creating a popular music piece by responding to a brief given to all participants. The brief did not include a detailed instruction for the instrumentation. Instead, participants were asked to work on a composition referencing Christmas. The production process involved my interactions with four Ohm Studio users 
located in the USA, Italy and Poland. The list of participants, including their contribution to the project and location, can be found in the Appendix.

\section{The creative process}

The work on this project started with the use of public chat and a discussion that I had with User 5. We had agreed to work together and start writing a downtempo song with a Christmas theme, as per the description of a weekly collaboration event. I created the drums, while User 5 programmed an initial bass line and a synthesizer line. On the first day, User 5 decided to stop his participation due to lack of interest in developing this composition further. On the same day, User 2 joined the public project and recorded a male lead vocal part, giving the song a strong sense of melodic and lyrical direction. This user contributed his own lyrics, which told the story of the historical figure associated with the mythical Santa Claus. The mix of the project at the end of the first day of work can be heard in Audio 1.

http://www.iaspmjournal.net/index.php/IASPM_Journal/article/downloadSuppFile/822/242

As the project was left open to the public, several other Ohm Studio users joined in within the next 11 days. However, only one of these new project members, User 3 , provided a musical contribution-the female vocals for the chorus line. This contribution constituted another important compositional element. At this point I felt that the composition included all key parts, and as the only remaining project instigator I became its sole producer, responsible for the direction of the song.

Five days after the female vocals were added, I invited User 4 (a friend located overseas) to contribute a bass line to the song. Being new to the software, this user needed guidance in order to learn the basics of the software and to establish his recording set-up. My translation of various lessons regarding the platform was also required, because the user did not speak English. This demonstrates how nonEnglish speaking music producers can be disadvantaged in relation to learning RMCS. Two days were spent on tutoring before the recording of the bass line, and some technical problems regarding his equipment also needed to be resolved. I continued to act as a technical instructor throughout the remainder of User $4^{\prime}$ s participation in the project.

Shortly after the new bass line was added, I changed the project status to "private", which prevented new participants from joining in without an invitation. This decision was triggered a day earlier, when I read comments of an Ohm Studio user on the public chat. He wrote about problems that he encountered with his public projects being changed by other members who destroyed previously crafted mix balances. On the technical side, the software features an efficient backup system. The 'snapshot' ${ }^{2}$ creation tool allows for an automated as well as an user determined project backup. This helps to ease anxiety around other users being able to modify the project.

Throughout the next two weeks I continued working with User 4 on improving and expanding his initial bass line recording. I also contacted User 2 about recording his vocals for the second verse, as this element was still missing. After my initial contact about expanding his vocal contribution, it took almost three months before this user added new vocal takes. During that time, I continued working on my musical additions to the composition. This included adding a jingle bells track which I generated through, and re-imported from, Ableton Live, where I could use a specific instrument with a distinct sound. Moreover, I added several new drum elements such as bongos, snares, cymbals, fills and sweeps. I also created multiple 
automation lanes on plug-ins and tracks, performed several other mixing operations, and worked on editing various tracks as well as fine-tuning the song structure. I eventually completed the first mix and mastered it using iZotope Ozone 6 software. This mastered version demonstrates production and mixing possibilities in Ohm Studio and it can be heard in Audio 2.

http://www.iaspmjournal.net/index.php/IASPM_Journal/article/downloadSuppFile/822/259

Several weeks later I migrated selected stems of the composition to Ableton Live in order to experiment with additional elements of the arrangement. The key reason for this move was that Ableton Live seemed to be better suited, at this point, for musical experimentation concerning the implementation of sampling. The move outside of Ohm Studio had the added benefit of being able to experiment with different song tempos. I eventually settled on the tempo of 97 BPM. This version of the composition was published on the Las Machinas label (KOshowKO 2016) as a fundraising single for the Australian Children's Music Foundation (Audio 3).

http://www.iaspmjournal.net/index.php/IASPM Journal/article/downloadSuppFile/822/260

In regard to RMCS-based forms of communication utilized in the project work, the tool used most frequently was private chat employing text-based communication. In addition, I used private messaging to contact active project members outside of the synchronous recording and production sessions. I also incorporated Facebook messenger and video chat extensively while communicating with User 4, with whom I already worked prior to this project and established various forms of communication outside of RMCS. These tools were critical to finding collaborators, maintaining creative relationships, discussing direction, and progressing the project to its conclusion.

\section{Evaluation of the work}

The speed of the creative process within RMCS can be fast and the core structure of the song can be created quickly through various additions contributed spontaneously by collaborators. All the vocal and lyrical contributions were provided without consultation with other project members. They consequently responded to ideas that were put in place. Similar to many of my other RMCS projects, "The Giver" is an example of improvisational collaboration (Sawyer 2007). The initial songwriting was spontaneous and led to contributions adherent to the predetermined theme, despite the limited preliminary co-ordination. While the early song development was fast, it slowed down over time and the remaining elements of the composition took several weeks to develop and finalize.

The image of Ohm Studio that emerged from working on this composition was that it is a democratic system. It enables unprecedented freedom of creative expression where input of several users can be provided at a rapid pace. The choice between synchronous and asynchronous sessions means that the latter allow delegation of tasks and the creation and recording of additional parts by users from around the world. Participants were encouraged to take risks, which is an approach that can nourish creativity (Leonard and Swap 2005). Reflecting on his creative process, Daniel Swiader, who contributed the bass line, asserts that:

The most pleasant part of working in Ohm Studio's sessions opened to the public is that one does not know what will happen next and what you will find in your session upon login. This is how collaborators can stimulate one another 
and it is a fundamental force in collective creativity (E-mail communication, 8 October 2017).

Drawbacks to this particular creative process included an occasional lack of clarity as to who is responsible for specific future actions like, for example, mixing. As the person who initiated this project I took on roles such as mixing and mastering engineer. Yet, I can imagine that a similar lack of clarity could impact negatively on projects with less defined role divisions. In their research on group creativity within organizations, Bolinger, Bonner and Okhuysen (2009: 268) define the "glue role" within a group. This role refers to actions taken by an individual who completes otherwise neglected tasks that are important to an overall group's performance. This definition is aligned with the role of a producer engaged in RMCS projects and I often found myself working in this role.

In this project, most participants did not initiate a discussion regarding new additions, such as lyrics or recorded vocal tracks. This is, however, not necessarily a negative aspect of project work, as it allows rapid contributions which can often be perfectly suitable, as was the case here. Presumably, the impact of such behaviour can vary in other projects executed with RMCS. Since multiple users can affect various parameters of the project while working synchronously, it is of utmost importance to learn early in the process which mixing actions are public and which are private. The ability to have this distinction is an important feature of Ohm Studio but it can frustrate newcomers if they do not understand the mechanics of this process. Speaking of his perception of how to navigate a session with multiple contributors, Swiader maintains that "[f]inding the order in a session is natural and spontaneous. In an unforced way, Ohm Studio stimulates the ability of finding one's role and function within the group" (E-mail communication, 8 October 2017).

As the production progressed, I discovered that in comparison to face-to-face non-RMCS based projects, an extended time was needed in order to be able to effectively communicate musical ideas as well as the direction of the project. In light of this, the lack of immediacy in the virtual environment does extend the time required to accomplish a project's creative objectives and finalize the work. However, I anticipate that a longer-term virtual collaboration could lead to establishing effective ways of working among the collaborators, which could lead to an improved workflow and more successful communication strategies. One major obstacle here would be the difficulty in maintaining collaborations over a long time, especially if collaborating musicians never had the opportunity to meet in non-virtual settings. On the other hand, the ability to work online with someone who we also know in person strengthens the virtual relationship and the work practice. This has been my experience when collaborating extensively online with User 4, whom I also knew from face-to-face contact. Vocal contributions from users 2 and 3 were made possible because the project was open to the entire Ohm Studio community. Creation of vocal lines was an example of a natural progression of the project and a way of my crowdsourcing of the musical input, which I define as passive. This passivity is evidenced in lack of my direct contact with these participants prior to receiving their initial musical contributions.

\section{Conclusion}

This project demonstrates that RMCS groups tend to be small, which increases the scope of user participation. I found my collaborators responsive and committed to achieving the best possible musical outcomes. Users who joined the project 
temporarily, without contributing anything, were not disruptive and their interest in the project illustrates the crowdsourcing process in RMCS public sessions. Attracting the largest possible group at an early stage of work helps in finding members with the highest level of interest in a given composition. I suggest that making projects private, once they are sufficiently developed and all required musical roles are secured, helps to finalize work without interruptions in the form of unwanted late modifications from newcomers.

Referring to the domain of music production, Lefford asserts that it "arises out of the co-workings of various experts-experts in playing musical instruments, in sound engineering, song writing" (2015). The above statement describes my creative process and received contributions and it also resonates with Csikszentmihalyi's observation that "an idea or product that deserves the label 'creative' arises from the synergy of many sources and not only from the mind of a single person" (2013). Stokes (2006) notes that creativity can be enhanced by constraints and lists task, goal, subject, and contrast constraints in relation to music. While my research was not specifically focused on examining the creative process of music production but rather the environment in which production took place, working with RMCS could be seen as a way of overcoming the constraint of not having suitable local collaborators. In addition, the process of producing music within RMCS involves certain constraints, for example the lack of immediacy concerning non-synchronous work and the importance of publicly sharing one's work in an embryonic, often unpolished form of a demo in order to attract collaborators. Speaking of his perception of the impact of RMCS on the music making process, my collaborator Herman Dexter stated:

This is the only way I write music nowadays. And the workflow of Ohm Studio has definitely affected the way I compose/record in a good way. As the motto of Ohm Studio states: 'Together is Better', I totally agree with that. I used to play guitar but only so-so. Now I write with guitarists that are leagues above me musically and I am much happier to focus on singing, melody, lyrics, or adapting pre-existing lyrics to a song (E-mail communication, 12 November 2015).

The music created for the purpose of this project exemplifies that RMCS impacts on collaboration in various ways. Musicians are no longer limited by their localities and, as a result, can choose from a large network of international collaborators. As stated above, these collaborators are often experts in their field, capable of contributing high quality material. The skills, ideas, and instruments of our collaborators become absorbed in our projects. RMCS-based interactions enhance individual learning with access to help and feedback from a wider community of practitioners. Furthermore, many RMCS platforms, including Ohm Studio, offer free access to their basic features democratizing collaborative music production tools.

The experience of synchronous communication facilitated by tools such as chat services enriches connectivity between users and enhances engagement, as participants experience changes collectively and discuss them in real time. Songwriting actions, such as the creation of new musical lines, can have immediate impact on collaborators working in synchronous systems. This in turn permits a response that enables participants to shape the composition in a more interactive way than in asynchronous software, where users are unaware of the actions of the collaborator until the project is published. Swiader sees another meaning to the collective process and argues that: "Ohm Studio has some therapeutic qualities: it 
teaches collaboration where there is no room for musical egocentrism, which can be common among some musicians" (E-mail communication, 8 October 2017).

In the course of undertaking this project, framed through a lens of practice-led enquiry, I have been able to demonstrate that communities of RMCS users enrich the production process and fill specific skills gaps as identified by the music producer. "The Giver" represents a creatively rewarding musical process. It demonstrates what can be achieved in popular music production when users take time to build and sustain relationships with members of the RMCS community, and thus understand how to effectively use available communication and production tools.

\section{Endnotes}

1. These notes can be inserted anywhere in the project and used for basic messaging with no advanced formatting.

2. The term 'snapshot' in Ohm Studio refers to the ability to save the current state of the project. The software does this automatically at regular time intervals and at the close down of a project but project administrators can also create custom made snapshots at any given time.

\section{References}

\section{Bibliography}

Alexandraki, C. and Valsamakis N. 2009. Enabling Virtual Music Performance Communities. In D. Akoumianakis Ed. Virtual Community Practices and Social Interactive Media: Technology Lifecycle and Workflow Analysis, Hershey, PA: IGI Global, 378-399.

Barbosa, Á. 2003. Displaced Soundscapes: A Survey of Network Systems for Music and Sonic Art Creation. Leonardo Music Journal 13: 53-59. http://dx.doi.org/10.1162/096112104322750791

Bolinger, A. R., Bonner, B. L. and Okhuysen, G. A. 2009. Sticking Together: The Glue Role and Group Creativity. In E. A. Mannix, J. A. Goncalo and M. A. Neale Eds. Creativity in Groups. Bingley: Emerald Publishing: 267-289.

Burgess, R. J., 2013. The Art of Music Production: The Theory and Practice. New York: Oxford University Press.

Csikszentmihalyi, M. 2013. Creativity: The Psychology Of Discovery and Invention. New York: Harper Perennial Modern Classics.

Duckworth, W. 2005. Virtual Music: How the Web got Wired for Sound. New York: Routledge.

Frith, S. and Zagorski-Thomas, S. (Eds.) 2012. The Art Of Record Production: An Introductory Reader for a New Academic Field. Farnham: Ashgate.

Hugill, A. 2005, Internet music: An introduction. Contemporary Music Review 24 (6): 429-437. http://dx.doi.org/10.1080/07494460500296094

Koszolko, M. 2015. Crowdsourcing, Jamming and Remixing: A Qualitative Study of Contemporary Music Production Practices in the Cloud. Journal on the Art of Record Production 10. http://arpjournal.com/crowdsourcing-jamming-andremixing-a-qualitative-study-of-contemporary-music-production-practices-inthe-cloud/. Accessed: 2 February 2017. 
Lefford, M. N. 2015. The Sound of Coordinated Efforts: Music Producers, Boundary Objects and Trading Zones. Journal on the Art of Record Production 10. http://arpjournal.com/the-sound-of-coordinated-efforts-music-producersboundary-objects-and-trading-zones/. Accessed: 3 November 2016.

Leonard, D. and Swap, W., 2005. When Sparks Fly: Harnessing the Power of Group Creativity. Boston: Harvard Business School Press.

McIntyre, P. 2006. Creative Practice as Research: 'Testing Out' the Systems Model of Creativity through Practitioner Based Enquiry. In Speculations and Innovations: Applying Practice Led Research in the Creative Industries. Brisbane: Queensland University of Technology. Available at: http://arts.brighton.ac.uk/_data/assets/pdf_file/0019/43093/McintyreP.pdf Accessed: 3 November 2016.

Sawyer, K. 2007. Group Genius: The Creative Power of Collaboration. New York: Basic Books.

Smith, H. and Dean. R. T., 2009. Practice-led Research, Research-led Practice in the Creative Arts. Edinburgh: Edinburgh University Press.

Stokes, P. D. 2006. Creativity From Constraints: The Psychology Of Breakthrough. New York: Springer.

Théberge, P. 2004. The Network Studio: Historical and Technological Paths to a New Ideal in Music Making. Social Studies of Science 34 (5): 759-781. http://dx.doi.org/10.1177/0306312704047173

Whalley, I. and Fields, K., 2012. Editorial. Organised Sound 17: 1-3. http://dx.doi.org/10.1017/S1355771811000586

Whalley, I. 2016. New Zealand Electroacoustic Music: Ruptures and Digital Networks. New Zealand Musicological Society Annual Conference, the University of Waikato Conservatorium of Music, Hamilton, 19 - 20 November 2016.

\section{Discography}

KOshowKO. 2016. The Giver (Download): Las Machinas 004. Available at: https://philosophyofsound.bandcamp.com/album/the-giver. Accessed: 8 October 2017.

\section{Appendix}

\section{Project participants:}

User 1

Name: Martin K. Koszolko

Contribution to the project: composition, production, synthesizers and drum programming, mixing, mastering

Location: Melbourne, Australia

User 2

Name: Herman Dexter

Contribution to the project: composition, production, male vocalist

Location: New Jersey, USA

User 3

Name: Stefania Fogliato 
Contribution to the project: composition, female vocalist Location: Alba, Italy

User 4

Name: Daniel Swiader

Contribution to the project: bass guitar

Location: Warsaw, Poland

User 5

Name: undisclosed

Contribution to the project: synthesizer programming Location: undisclosed city, USA 